\title{
Characteristics of Heat Illness during Hajj: A Cross-Sectional Study
}

\author{
Doaa A. Abdelmoety ${ }^{(D)},{ }^{1}$ Nahid K. El-Bakri, ${ }^{2}$ Wedian O. Almowalld, ${ }^{1}$ \\ Zyad A. Turkistani, ${ }^{3}$ Bassam H. Bugis, ${ }^{3}$ Eshraq A. Baseif, ${ }^{1}$ Mohamed H. Melbari, ${ }^{4}$ \\ Khaled AlHarbi, ${ }^{5}$ and Amani Abu-Shaheen $\mathbb{D}^{2}$ \\ ${ }^{1}$ Clinical Research Management Department, Executive Administration of Research, King Abdullah Medical City in Holy Capital, \\ Makkah, Saudi Arabia \\ ${ }^{2}$ Research Center, King Fahad Medical City, Riyadh, Saudi Arabia \\ ${ }^{3}$ Medical College, Umm Al-Qura University, Al Taif Road, Makkah 24382, Saudi Arabia \\ ${ }^{4}$ Planning and Research Department, General Directorate of Health Affairs, Makkah, Saudi Arabia \\ ${ }^{5}$ Emergency Hospital At Mina, Makkah 24243, Saudi Arabia
}

Correspondence should be addressed to Doaa A. Abdelmoety; doaa_93@hotmail.com

Received 12 December 2017; Revised 4 January 2018; Accepted 21 January 2018; Published 14 February 2018

Academic Editor: Gianluca Coppola

Copyright ( 2018 Doaa A. Abdelmoety et al. This is an open access article distributed under the Creative Commons Attribution License, which permits unrestricted use, distribution, and reproduction in any medium, provided the original work is properly cited.

Introduction. Data regarding the characteristics and outcomes of heat illness are lacking in the literature. The present study aimed to identify the clinical characteristics, morbidity, management, and mortality associated with heat illness among Hajj participants. Methods. A cross-sectional study was conducted during the Hajj in 2016 on patients who presented to emergency departments and were diagnosed with heat exhaustion or heatstroke. Data were collected using a structured collection sheet developed based on the literature. Results. A total of 267 patients were recruited. Of these, 80 (29\%) and $187(67.75 \%)$ were diagnosed with heatstroke and heat exhaustion, with $6.3 \%$ and $0.0 \%$ mortality, respectively. The mean age of the patients was $54.0 \pm 16$ years. Diabetes mellitus was the most common comorbidity among both heatstroke and heat exhaustion patients. The majority of patients had hyperthermia and electrolyte imbalance. Most of the heat illness cases were treated per heat illness guidelines. Conclusions. Although authorities are working on research and forming interdisciplinary teams to prevent health problems during the Hajj, the mortality rate from heatstroke is high and the majority of the patients had hyperthermia, varied signs and symptoms, elevated creatinine levels, and electrolyte imbalances.

\section{Introduction}

The average global temperature has been estimated to increase in the summer months by $0.6^{\circ} \mathrm{C}$ per century [1]. Heat-related illness results in at least 70,000 fatalities annually in Europe [2] and more than 1,300 deaths per year in the United States [3]. High temperatures during the summer season are associated with heat illness, which can range from minor (heat cramps, edema, prickly heat, and syncope) to serious conditions (heat exhaustion or heatstroke) [4]. Many factors play a role in the outcome of heat illness, including old age, chronic disease, overcrowding, physical exertion, lack of acclimatization, and dehydration. A lack of proper treatment could exacerbate the condition to organ failure, convulsions, coma, and increasing intracranial pressure $[5,6]$. Accordingly, Hajj, an Islamic pilgrimage, is one of the largest mass gathering challenges for the Kingdom of Saudi Arabia and the Ministry of Health. Hajj is the fifth pillar of Islam and it is mandatory for Muslims to perform Hajj at least once in their lifetime if they are financially and physically capable. It attracts more than 2.5 million pilgrims from many countries, who assemble in Makkah over a 1-week period [7]. Depending on the Islamic (lunar) calendar, Haij may occur during the summer season, when the temperature can exceed $45^{\circ} \mathrm{C}$. 
The Saudi Ministry of Health, in collaboration with the Hajj Committees, prepares for emergencies during Hajj as well as for communicable and noncommunicable diseases [8] by providing the necessary equipment, facilities, and trained staff to hospitals in Mina, El-Mashaeer, and Makkah [9-11].

Previous studies have investigated different aspects of heat illness in Saudi Arabia, including the epidemiology [12] and environmental conditions [13] by evaluating changes in climatic heat, and heat illness as a noncommunicable disease $[8,10,11]$. Moreover, studies are lacking in the literature regarding disease course and patient characteristics, treatments, outcomes, and complications of heat illness during Hajj [14]. Earlier studies have focused on the variables and clinical information that affect medical needs during Hajj for a specific hospital or area $[8,15-17]$. However, a systematic approach to data collection that includes multiple hospitals and areas with a focus on heat illness has not been performed. Therefore, the aim of the present study was to identify the type, clinical characteristics, risk factors, laboratory profiles, morbidity, medical management, and mortality associated with heat illness among Hajj participants. The results of this study might provide information on the hazards to be expected during the summer season and offer guidance to Hajj authorities.

\section{Materials and Methods}

2.1. Study Design. A prospective cross-sectional study was conducted during the Hajj in 2016 at four hospitals in the Mena region (Mena Emergency Hospital, Mena Alwadi Hospital, Mena Alshareih Algadeid Hospital, and Mena Aljassir Hospital) and four hospitals in the Arafat region (Namera Hospital, Jabal Elrahmah Hospital, East Arafat Hospital, and Arafat General Hospital) of Saudi Arabia.

2.2. Participants. Patients who presented to the emergency departments of any of the eight hospitals and who were diagnosed with heat exhaustion or heatstroke were included in this study. Heat exhaustion was defined as mild-tomoderate heat-related illness owing to the exposure to high environmental heat; the signs and symptoms included intense thirst, weakness, discomfort, anxiety, dizziness, and syncope; the temperature could be normal or slightly elevated, $>37^{\circ} \mathrm{C}$ $\left(98.6^{\circ} \mathrm{F}\right)$, but less than $40^{\circ} \mathrm{C}\left(104^{\circ} \mathrm{F}\right)$. Heatstroke was defined as a severe heat-related illness characterized by a core temperature $>40^{\circ} \mathrm{C}\left(104^{\circ} \mathrm{F}\right)$ and central nervous system abnormalities resulting from passive exposure to environmental heat [18].

2.3. Data Collection. Data were collected through a structured collection sheet which was developed through an indepth review of the literature [18]. The data collection sheet included information ascertaining: (i) patient clinical characteristics (vital signs, comorbidities, and signs and symptoms), (ii) laboratory profiles (blood gas, electrolytes, liver and kidney enzymes, hemoglobin, platelets, and glucose), (iii) medical management (ensuring airway patency, rehydration, cooling, and management of complications if any), and (iv) outcomes (improved and discharged, refused treatment, transferred to another hospital, discharged against medical advice, or died). Demographic data, including patient age, nationality, Hajj or non-Hajj participant, and gender, were also collected.

2.4. Ethical Considerations. The Institutional Review Board of King Abdullah Medical City exempted the study protocol from obtaining ethical approval.

2.5. Statistical Analysis. Data were analyzed using IBM SPSS Statistics for Windows, version 22.0 (IBM Corp., Armonk, NY, USA). Numeric data were presented as means \pm standard deviations (SDs) or medians and interquartile ranges (IQRs) according to the type of distribution, while categorical variables were presented as percentages. $t$-test and Chi-square and Fisher's exact tests were used as appropriate.

\section{Results}

3.1. Demographic Characteristics. During the study period, 267 patients were recruited. Of these, 80 (29\%) and 187 $(67.75 \%)$ were diagnosed with heatstroke and heat exhaustion, respectively. The mean age of the patients was $54.0 \pm 16$ years (median: 58 years, range: $20-100$ years). A total of 143 $(54.6 \%)$ patients were male. The patients were residents of 30 different countries. Most patients were from India (16.7\%), Egypt (16.7\%), Indonesia (11.1\%), Saudi Arabia (8.9\%), and Pakistan (8.5\%), and $38.1 \%$ were of other nationalities. Mina Alwadi and Mina Emergency Hospitals received the most number of patients with heatstroke (29 [36.3\%] and 16 [20.0\%] patients, resp.). Mina Aljassir Hospital received the most number of heat exhaustion cases (71 [38.0\%] patients).

The mean ages of the patients with heatstroke and heat exhaustion were $57.41 \pm 12.35$ and $52.49 \pm 17.70$ years, respectively. The majority of patients in both groups were male $(58.7 \%$ and $52.4 \%$, resp.).

\subsection{Clinical Characteristics}

3.2.1. Comorbidities. Among the patients with heatstroke, $15.0 \%$ had diabetes; however, only $5.9 \%$ of patients with heat exhaustion had diabetes $(p=0.029)$ (Table 1$)$.

3.2.2. Vital Signs. Patients with heat exhaustion and with heatstroke had recorded temperatures of $<40^{\circ} \mathrm{C}$ and $>40^{\circ} \mathrm{C}$, respectively. The vital signs of the two groups are presented in Table 2.

3.2.3. Signs and Symptoms. Altered mental status (50 patients, $62.5 \%$ ), tachycardia (37 patients, $46.3 \%$ ), and tachypnea (29 patients, $36.3 \%$ ) were the most common signs and symptoms among patients with heatstroke. Dizziness (40 patients, $21.4 \%$ ) and vomiting (20 patients, 10.7\%) were the most common signs and symptoms among patients with heat exhaustion (Table 3). However, a statistically significant difference was only found between heatstroke, heat exhaustion, and irritability $(p=0.028)$.

3.3. Laboratory Results. Physicians requested blood gas, clinical chemistry, and complete blood profiles for some patients according to their medical conditions. Among those with 
TABLE 1: Comorbidities of patients with heatstroke and heat exhaustion.

\begin{tabular}{|c|c|c|c|}
\hline Variable & $\begin{array}{c}\text { Heatstroke } \\
n=80\end{array}$ & $\begin{array}{c}\text { Heat exhaustion } \\
n=187\end{array}$ & $p$ value \\
\hline \multicolumn{4}{|c|}{ Cardiovascular disease } \\
\hline Yes & $2(2.5)$ & $4(2.2)$ & \multirow{2}{*}{1.000} \\
\hline No & $78(97.5)$ & $183(97.8)$ & \\
\hline \multicolumn{4}{|c|}{ Diabetes mellitus } \\
\hline Yes & $12(15.0)$ & $11(5.9)$ & \multirow{2}{*}{$0.029^{*}$} \\
\hline No & $68(85.0)$ & $176(94.1)$ & \\
\hline \multicolumn{4}{|c|}{ Hypertension } \\
\hline Yes & $5(6.3)$ & $8(4.3)$ & \multirow{2}{*}{0.539} \\
\hline No & $75(93.7)$ & $179(95.7)$ & \\
\hline
\end{tabular}

Data presented as numbers (percentages). ${ }^{*} p$ value is statistically significant.

TABLE 2: Vital signs of patients with heatstroke and heat exhaustion.

\begin{tabular}{lccc}
\hline Vital signs & $\begin{array}{c}\text { Heatstroke } \\
n=80 \\
\text { Mean } \pm \text { SD }\end{array}$ & $\begin{array}{c}\text { Heat exhaustion } \\
n=187 \\
\text { Mean } \pm \text { SD }\end{array}$ & $p$ value \\
\hline $\begin{array}{l}\text { Systolic blood } \\
\text { pressure (mm Hg) }\end{array}$ & $126 \pm 24$ & $123 \pm 20$ & 0.493 \\
$\begin{array}{l}\text { Diastolic blood } \\
\text { pressure (mm Hg) }\end{array}$ & $76 \pm 17$ & $72 \pm 13$ & 0.177 \\
$\begin{array}{l}\text { Respiratory rate } \\
\text { (breaths/minute) }\end{array}$ & $25 \pm 14$ & $30 \pm 24$ \\
$\begin{array}{l}\text { Pulse rate } \\
\text { (beats/minute) }\end{array}$ & $110 \pm 21$ & $98 \pm 18$ & 0.454 \\
\hline
\end{tabular}

${ }^{*} p$ value is statistically significant.

heatstroke, the blood gas investigations indicated partially compensated metabolic acidosis with hypoxemia in 26 (33\%) patients. All blood gas values were normal in patients with heat exhaustion, except for decreased oxygen partial pressure $\left(\mathrm{pO}_{2}\right)$ values in $24(19 \%)$ patients, indicating hypoxemia.

The top four abnormal results among patients with heatstroke were high glucose level (36 patients, 45.0\%), high creatinine concentration (33 patients, $41.3 \%$ ), hyponatremia (21 patients, 26.3\%), and high blood urea nitrogen (BUN) concentration (21 patients, $26.3 \%$ ). In comparison, hyponatremia (18 patients, 9.6\%), hypokalemia (18 patients, 9.6\%), high glucose level (15 patients, $8.5 \%$ ), and high BUN concentration (15 patients, 8.0\%) were the top abnormal results among patients with heat exhaustion (Table 4).

Statistical significant difference was found between heatstroke, heat exhaustion, and the following laboratory tests: high glucose level $(p=0.004)$, high creatinine $(p=<$ $0.001)$, hyponatremia $(p=0.046)$, high BUN $(p=0.023)$, hypokalemia $(p=0.045)$, low platelets (PLT) $(p=0.003)$, low hemoglobin $(\mathrm{Hb})(p=0.037)$, and high white blood cell (CK) $(p=0.044)$.

3.4. Management and Outcomes. Measures to ensure airway patency and intubation were provided to 51 (63.8\%) heatstroke and $9(4.8 \%)$ heat exhaustion patients. Rehydration by intravenous line, cardiac monitor, and Foley catheter were provided to $64(80 \%)$ heatstroke and $20(10.7 \%)$ heat exhaustion patients. Most of the patients with heat illness were managed with the use of a fan, water spray, and ice packs to reduce the body temperature. The median length of the hospital stay was two hours (IQR, 1-12 hours), with a maximum stay of 57 hours. Around $84.3 \%$ of patients with heatstroke improved and were discharged; however, $7.1 \%$ died and $5.7 \%$ were admitted to critical care units. Of the 178 patients with heat exhaustion, $162(94.7 \%)$ improved and were discharged, 7 (4.1\%) discharged against medical advice, 2 (1.2\%) were admitted to critical care units, and none died $(p=0.001)$ (Table 5).

\section{Discussion}

The results of the present study provide extensive data regarding the types, clinical characteristics, laboratory profiles, morbidity, medical management, and mortality due to heat illness among pilgrims. Heat illness can be prevented with strategic planning and preventive measurements. A 2012 systematic review of weather and environmental hazards at mass gatherings showed that a one-degree increase in temperature, from $20^{\circ} \mathrm{C}$ to $21^{\circ} \mathrm{C}$, resulted in an $11 \%$ increase in the number of individuals requiring medical attention. Moreover, temperatures exceeding $27^{\circ} \mathrm{C}$ resulted in an increase in the incidence of patient presentations [19]. Thus, the government of Kingdom of Saudi Arabia, in collaboration with the Ministry of Hajj, is taking measures to prevent health 
TABLE 3: Signs and symptoms of patients with heatstroke and heat exhaustion.

\begin{tabular}{|c|c|c|c|}
\hline Vital signs & $\begin{array}{c}\text { Heatstroke } \\
n(\%)\end{array}$ & $\begin{array}{c}\text { Heat exhaustion } \\
n(\%)\end{array}$ & $p$ value \\
\hline Altered mental status & $50(62.5)$ & $7(4)$ & 0.315 \\
\hline Tachycardia & $37(46.3)$ & $7(4)$ & 0.285 \\
\hline Tachypnea & $29(36.3)$ & $4(2.1)$ & 0.422 \\
\hline Hypotension & $19(23.8)$ & $3(1.6)$ & 0.474 \\
\hline Convulsions & $11(13.8)$ & $1(0.5)$ & 0.693 \\
\hline Diarrhea & $5(6.3)$ & $1(0.5)$ & 0.337 \\
\hline Dizziness & $1(1.2)$ & $40(21.4)$ & 0.412 \\
\hline Vomiting & 0 & $20(10.7)$ & 0.052 \\
\hline Headache & 0 & $14(7.5)$ & 0.061 \\
\hline Irritability & $1(1.2)$ & $12(6.4)$ & $0.028^{*}$ \\
\hline Nausea & 0 & $6(3.2)$ & 0.058 \\
\hline Postural hypotension & 0 & $4(2.1)$ & 0.099 \\
\hline
\end{tabular}

* $p$ value is statistically significant.

TABLE 4: Laboratory profiles of the study's participants.

\begin{tabular}{lccc}
\hline Test & Heatstroke $n(\%)$ & Heat exhaustion $n(\%)$ & $p$ value \\
\hline High glucose level & $36(45.0)$ & $15(8.5)$ & $\mathbf{0 . 0 0 4}^{*}$ \\
High creatinine & $33(41.3)$ & $9(4.8)$ & $<\mathbf{0 . 0 0 1}^{*}$ \\
Hyponatremia & $21(26.3)$ & $18(9.6)$ & $\mathbf{0 . 0 4 6}^{*}$ \\
High BUN & $21(26.3)$ & $15(8.0)$ & $\mathbf{0 . 0 2 3}^{*}$ \\
Hypokalemia & $20(25.0)$ & $18(9.6)$ & $\mathbf{0 . 0 4 5}^{*}$ \\
Low PLT & $17(21.3)$ & $13(7.3)$ & $\mathbf{0 . 0 0 3}^{*}$ \\
Low Hb & $16(20.0)$ & $12(6.4)$ & $\mathbf{0 . 0 3 7}^{*}$ \\
High WBC & $13(16.2)$ & $8(4.3)$ & 0.610 \\
High CK & $13(16.3)$ & $10(5.3)$ & $\mathbf{0 . 0 4 4 ^ { * }}$ \\
High AST & $10(12.5)$ & $4(2.1)$ & 1.000 \\
High LDH & $8(10)$ & $5(2.7)$ & 0.165 \\
High ALT & $2(2.5)$ & 0.390 \\
\hline
\end{tabular}

BUN: blood urea nitrogen; PLT: platelets; Hb: hemoglobin; WBC: white blood cell; CK: creatinine kinase; AST: aspartate transaminase; LDH: lactate dehydrogenase; ALT: alanine transaminase. ${ }^{*} p$ value is statistically significant.

problems during the event [20]. During Hajj, participants are educated to stay in shelters for protection, use sunblock [21], perform proper handwashing, and ensure adequate water intake [22]. Also, participants are encouraged to be flexible with time, if possible, and perform rites during the night [21]. However, the results of the present study showed that out of 267 patients $80(29 \%)$ patients had heatstroke, the most severe form of heat illnesses, with mortality of $6.3 \%$.

In our study, the mean age of the patients was $54.0 \pm 16$ years, with a predominant proportion of males. Moreover, diabetes mellitus was the most common comorbidity among both heatstroke and heat exhaustion patients. Previous epidemiological studies have shown that the elderly and those with comorbidities have an increased risk of hospitalization due to heatstroke $[23,24]$.

Elderly people are susceptible to heat illness due to decreased blood flow to the skin, sweat gland function, cardiac output, thirst sensation, and renal function [25, 26]. Takahiro et al. reported age $\geq 65$ years, elevated body temperature, deterioration of consciousness, and high serum creatinine level to be the predictive factors of patient hospitalization [27]. Therefore, these factors can be used to identify a potentially severe condition in the early stage of illness before the condition worsens.

Since the central nervous system is sensitive to heat stress $[28,29]$, its dysfunction is a major symptom of hyperthermia $[23,29]$. In early period of heat illness, the common symptoms include anxiety, dizziness, fainting, and headache [5]. With progression to a pathological condition that leads to decreased cerebral blood flow and increased intracranial pressure, patients commonly experience delirium, convulsions, and coma $[6,28]$. Similarly, our study showed that patients with heatstroke had hyperthermia, altered mental status, tachycardia, convulsions, high creatinine level, and electrolyte imbalances. To prevent the unfavorable consequences of a delay in starting treatment, measurement of body temperature and consciousness level are simple but important indicators of the severity of heat illness. 
TABLE 5: Outcomes of patients with heatstroke and heat exhaustion.

\begin{tabular}{|c|c|c|c|}
\hline & Heatstroke $n(\%)$ & Heat exhaustion $n(\%)$ & $p$ value \\
\hline Improved and discharged & $59(84.3)$ & $162(94.7)$ & \\
\hline Died & $5(7.1)$ & 0 & \\
\hline Admitted to critical care units & $4(5.7)$ & $2(1.2)$ & $0.001^{*}$ \\
\hline Transferred to another hospital & $1(1.4)$ & 0 & \\
\hline Discharged against medical advice & $1(1.4)$ & $7(4.1)$ & \\
\hline
\end{tabular}

${ }^{*} p$ value is statistically significant.

Consistent with our findings regarding patient management of these illnesses, previous reports showed that Hajj participants were managed according to heat illness guidelines $[4,30]$ recommending cooling, fluid repletion, and blood tests to exclude organ damage, according to patient conditions. Preventive measures and awareness about the dangers of dehydration, as well as encouraging Hajj participants to drink sufficient fluids, seek shade, and recognize the symptoms of dehydration, may reduce the incidence of heat illness. Similar measures have been reported to decrease the incidence of heat illness in other mass gatherings [31].

Hajj authorities are working on research, education, and the formation of interdisciplinary teams comprising environment specialists and health experts [30]. Studies on Hajj in the past decade have encouraged research and planning [21], which led to a massive reduction in the incidences of communicable diseases that were major causes of mortality $[15,16]$. However, noncommunicable diseases remain an issue, especially for individuals with comorbidities, those in older age groups, and those living in high-temperature locations $[15,17]$. Correspondingly, our results revealed a high rate of mortality from heatstroke.

Hajj is a major annual mass gathering of millions of people from all over the world, with different cultures, socioeconomic levels, knowledge, attitudes, and, most importantly, health statuses [30]. The causes of morbidities and mortalities among such a broad spectrum of people are varied [15, 21, 32]. However, with proper education and awareness measures, most of these causes can be reduced.

The current findings might provide a foundation for strategic planners to make better arrangements for Hajj participants during the summer season. Furthermore, our results confirm the importance of screening individuals in their home countries before Hajj based on selected criteria to exclude unfit persons from participating or to provide a fast-track process during Hajj.

Future interventional studies should highlight the importance of heat illness education and prevention.

\section{Conclusion and Recommendations}

The present study documented the demographic and clinical characteristics, mortality, and medical management of patients with serious heat illness, which may help to identify patients with mild-to-moderate heat illness who should be observed in emergency departments. Old age and diabetes mellitus were the most common risk factors for heat illness. Although authorities are working on research, education, and the formation of interdisciplinary teams comprising environment specialists and health experts and taking measures to prevent health problems during Hajj, the mortality rate due to heatstroke requires attention. In addition, the majority of patients had hyperthermia, varied signs and symptoms, elevated creatinine levels, and electrolyte imbalances. Increased patient education and awareness regarding heat illnesses may reduce the occurrence and consequences of these heat-related symptoms and illnesses.

\section{Ethical Approval}

This study has been granted an exemption from requiring ethics approval [IRB\# 16-281]. Accordingly, the consent to participate is not applicable.

\section{Conflicts of Interest}

The authors declare that they have no conflicts of interest.

\section{Acknowledgments}

The authors thank Dr. Khaled Salman, Executive Director of Research and Innovation Administration of King Abdullah Medical City in Holy Capital, for his help through the volunteer research assistant program and all research volunteers (Mrwah fallatah, Hasna Emam, Shorooq AlOrabi, Meaad AlMouwalled, Hamdan Alaklabi, Abdulaziz Al-Barakati, Abdualrahman Hassan, Abdulrhman Althaqafi, Saeed Alzahrani, Mohammed Alghamdi, Faris Muidh, Mohammed Al-Otaibi, Lujain Malaka, and Moath Alshanqity). They also thank Mr. Maher Alhazmi and Ms. Ahlam Rawah from the Registry Department for their help with designing the database. The authors also appreciate the support of the doctors and administrators at Mina and Arafat Hospitals.

\section{References}

[1] S. Solomon, D. Qin, M. Manning et al., Contribution of Working Group I to The Fourth Assessment Report of The Intergovernmental Panel On Climate Change, Cambridge University Press, Cambridge, New York, NY, USA, 2007.

[2] J.-M. Robine, S. L. K. Cheung, S. Le Roy et al., "Death toll exceeded 70,000 in Europe during the summer of 2003," Comptes Rendus Biologies, vol. 331, no. 2, pp. 171-178, 2008.

[3] M. C. Sarofim, S. Saha, M. H. Hawkins et al., "TemperatureRelated Death and Illness," in The Impacts of Climate Change on Human Health in the United States: A Scientific Assessment, 
pp. 43-68, U.S. Global Change Research Program, Washington, DC, USA, 2016.

[4] A Pocket Guide for Clinicians during Hajj 1437, Ministry of Health, King Fahd National Library Cataloging-in-Publication Data, 7th edition, 2016.

[5] W. F. Atha, "Heat-related illness," Emergency Medicine Clinics of North America, vol. 31, no. 4, pp. 1097-1108, 2013.

[6] Y. Epstein and W. O. Roberts, "The pathopysiology of heat stroke: an integrative view of the final common pathway," Scandinavian Journal of Medicine \& Science in Sports, vol. 21, no. 6, pp. 742-748, 2011.

[7] Z. Memish, S. McNabb, F. Mahoney et al., "Establishment of public health security in Saudi Arabia for the 2009 Hajj in response to pandemic influenza A H1N1," The Lancet, vol. 374, no. 9703, pp. 1786-1791, 2009.

[8] N. D. Dzaraly, N. I. A. Rahman, N. B. Simbak et al., "Patterns of communicable and non-communicable diseases in pilgrims during Hajj," Research Journal of Pharmacy and Technology, vol. 7, no. 9, pp. 1052-1059, 2014.

[9] Y. M. Arabi and S. M. Alhamid, "Emergency room to the intensive care unit in Hajj. The chain of life," Saudi Medical Journal, vol. 27, no. 7, pp. 937-941, 2006.

[10] N. A. Khan, A. M. Ishag, M. S. Ahmad, F. M. El-Sayed, Z. A. Bachal, and T. G. Abbas, "Pattern of medical diseases and determinants of prognosis of hospitalization during 2005 Muslim pilgrimage (Hajj) in a tertiary care hospital. A prospective cohort study," Saudi Medical Journal, vol. 27, no. 9, pp. 13731380, 2006.

[11] A. I. Sindy, M. J. Baljoon, N. A. Zubairi et al., "Pattern of patients and diseases during mass transit: The day of Arafat experience," Pakistan Journal of Medical Sciences, vol. 31, no. 5, article no. A025, pp. 1099-1103, 2015.

[12] M. Khogali, "Epidemiology of heat illnesses during the makkah pilgrimages in Saudi Arabia," International Journal of Epidemiology, vol. 12, no. 3, pp. 267-273, 1983.

[13] M. H. Noweir, A. O. Bafail, and I. M. Jomoah, "Study of heat exposure during Hajj (pilgrimage)," Environmental Modeling \& Assessment, vol. 147, no. 1-3, pp. 279-295, 2008.

[14] R. E. Gliklich and M. B. Leavy, Eds., Registries for Evaluating Patient Outcomes: A User's Guide, Rockville (MD): Agency for Healthcare Research and Quality (US), 3rd edition, 2014, https://www.ncbi.nlm.nih.gov/books/NBK208616/.

[15] Z. A. Memish, A. Zumla, R. F. Alhakeem et al., "Hajj: Infectious disease surveillance and control," The Lancet, vol. 383, no. 9934, pp. 2073-2082, 2014.

[16] P. Gautret, S. Benkouiten, S. Sridhar, J. A. Al-Tawfiq, and Z. A. Memish, "Diarrhea at the Hajj and Umrah," Travel Medicine and Infectious Disease, vol. 13, no. 2, pp. 159-166, 2015.

[17] S. Yezli, B. M. Alotaibi, and A. A. B. Saeed, "The Hajj Health Requirements: Time for a serious review?” The Lancet, vol. 387, no. 10021, pp. 845-846, 2016.

[18] G. S. Lipman, K. P. Eifling, M. A. Ellis, F. G. Gaudio, E. M. Otten, and C. K. Grissom, "Wilderness medical society practice guidelines for the prevention and treatment of heat-related illness: 2014 update," Wilderness \& Environmental Medicine, vol. 25, no. 4, pp. S55-S65, 2014.

[19] L. Soomaroo and V. Murray, "Weather and environmental hazards at mass gatherings," PLoS Currents, 2012.

[20] S. Shafi, O. Dar, M. Khan et al., "The annual Hajj pilgrimage-minimizing the risk of ill health in pilgrims from Europe and opportunity for driving the best prevention and health promotion guidelines," International Journal of Infectious Diseases, vol. 47, pp. 79-82, 2016.

[21] A. 1. Masud SMR, A. B. Asmidar, and S. Yussof, "Determining the types of diseases and emergency issues in Pilgrims during Hajj: a literature review," International Journal of Advanced Computer Science and Applications, vol. 7, no. 10, pp. 86-94, 2016.

[22] M. S. Galal and K. A. Salem, "Pattern of heat stroke and heat exhaustion among pilgrims . Over 20 years (1982-2001)," The Egyptian Journal of Community Medicine, vol. 21, no. 3, 2003.

[23] J. L. Glazer, "Management of heatstroke and heat exhaustion," American Family Physician, vol. 71, no. 11, pp. 2133-2142, 2005.

[24] J. C. Semenza, C. H. Rubin, K. H. Falter et al., "Heat-related deaths during the July 1995 heat wave in Chicago," The New England Journal of Medicine, vol. 335, no. 2, pp. 84-90, 1996.

[25] J. C. Semenza, J. E. McCullough, W. D. Flanders, M. A. McGeehin, and J. R. Lumpkin, "Excess hospital admissions during the July 1995 heat wave in Chicago," American Journal of Preventive Medicine, vol. 16, no. 4, pp. 269-277, 1999.

[26] W. L. Kenney and T. A. Munce, "Aging and human temperature regulation," Journal of Applied Physiology, vol. 95, no. 6, pp. 2598-2603, 2003.

[27] T. Yamamoto, M. Todani, Y. Oda et al., "Predictive factors for hospitalization of patients with heat illness in Yamaguchi, Japan," International Journal of Environmental Research and Public Health, vol. 12, no. 9, pp. 11770-11780, 2015.

[28] B. Yaqub and S. Al Deeb, "Heat strokes: Aetiopathogenesis, neurological characteristics, treatment and outcome," Journal of the Neurological Sciences, vol. 156, no. 2, pp. 144-151, 1998.

[29] A. Bouchama and J. P. Knochel, "Heat stroke," The New England Journal of Medicine, vol. 346, no. 25, pp. 1978-1988, 2002.

[30] A. Shujaa and S. Alhamid, "Health response to Hajj mass gathering from emergency perspective, narrative review," Turkish Journal of Emergency Medicine, vol. 15, no. 4, pp. 172-176, 2015.

[31] R. J. Brennan, M. E. Keim, T. W. Sharp, S. F. Wetterhall, R. J. Williams, E. L. Baker et al., "Medical and public health services at the 1996 Atlanta Olympic Games: an overview," Med J Aust, vol. 167, no. (11-12), pp. 595-598, 1997.

[32] S. Shafi, R. Booy, E. Haworth, H. Rashid, and Z. A. Memish, "Hajj: Health lessons for mass gatherings," Journal of Infection and Public Health, vol. 1, no. 1, pp. 27-32, 2008. 


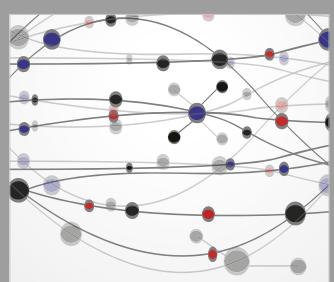

The Scientific World Journal
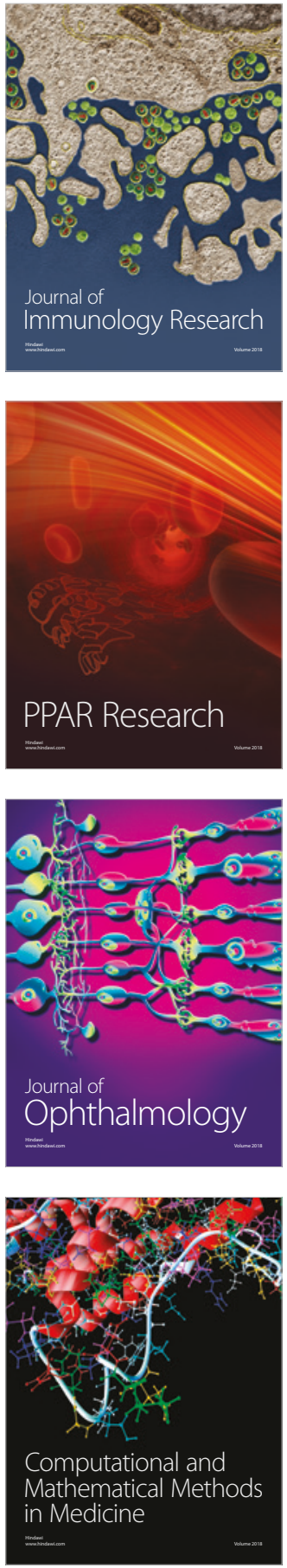

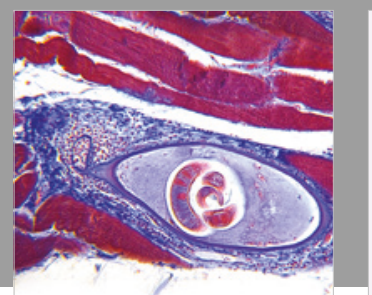

Gastroenterology Research and Practice

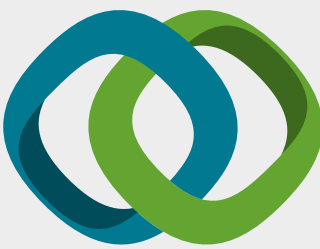

\section{Hindawi}

Submit your manuscripts at

www.hindawi.com
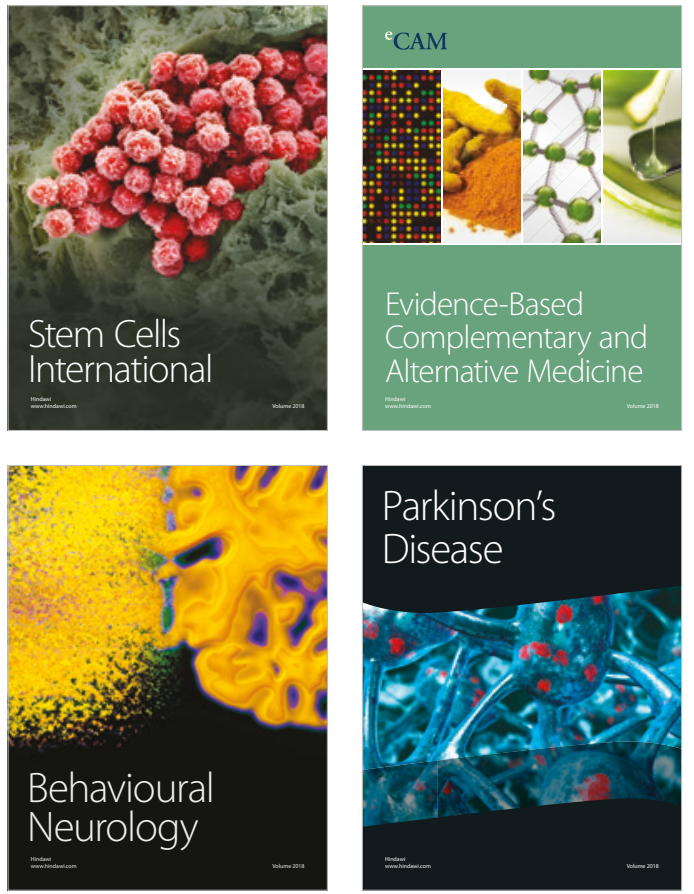

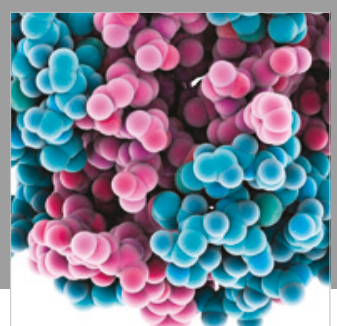

ournal of

Diabetes Research

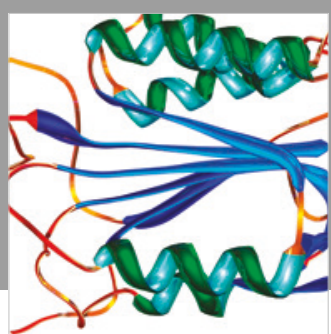

Disease Markers
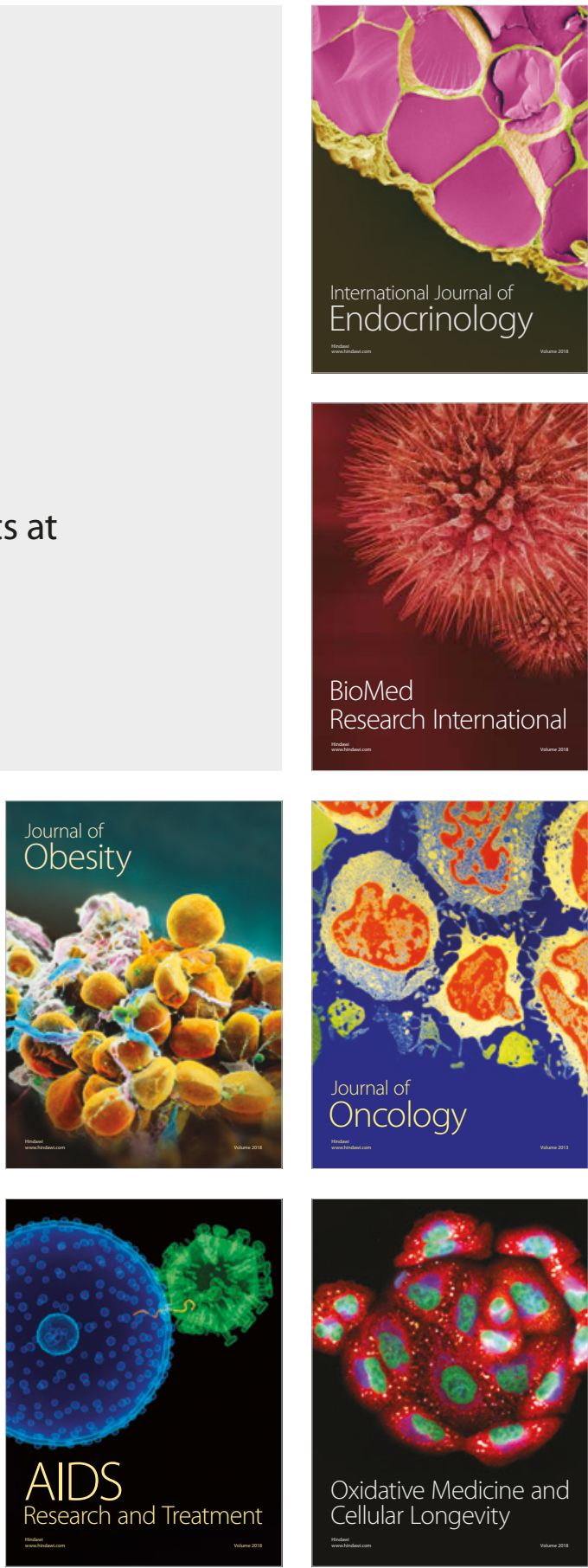